\title{
Contribution of molecular analyses in diagnosing Marfan syndrome and type I fibrillinopathies: an international study of 1009 probands
}

\author{
L Faivre, ${ }^{1,2} \mathrm{G}$ Collod-Beroud, ${ }^{3,4}$ A Child ${ }^{5}$ B Callewaert, ${ }^{6} \mathrm{~B}$ L Loeys,${ }^{6,7} \mathrm{C}$ Binquet, ${ }^{2,8}$ \\ E Gautier ${ }^{2,8} \mathrm{E}^{2}$ Arbustini, ${ }^{9} \mathrm{~K}$ Mayer, ${ }^{10} \mathrm{M}$ Arslan-Kirchner, ${ }^{11} \mathrm{C}$ Stheneur, ${ }^{12}$ \\ A Kiotsekoglou, ${ }^{5}$ P Comeglio, ${ }^{5} \mathrm{~N}$ Marziliano, ${ }^{9} \mathrm{D}$ Halliday, ${ }^{13} \mathrm{C}$ Beroud ${ }^{3,4,14}$ \\ C Bonithon-Kopp, ${ }^{2,8}$ M Claustres, ${ }^{3,4,14}$ H Plauchu, ${ }^{15} \mathrm{P}$ N Robinson, ${ }^{16} \mathrm{~L}$ Adès, ${ }^{17,18,19}$ \\ J De Backer, ${ }^{6}$ P Coucke, ${ }^{6}$ U Francke, ${ }^{20}$ A De Paepe, ${ }^{6}$ C Boileau, ${ }^{21}$ G Jondeau ${ }^{22}$
}

\begin{abstract}
Background: The diagnosis of Marfan syndrome (MFS) is usually initially based on clinical criteria according to the number of major and minor systems affected following international nosology. The number of FBN1 mutation carriers, at risk of aortic complications who would not be properly diagnosed based only on clinical grounds, is of growing importance owing to the increased availability of molecular screening. The aim of the study was to identify patients who should be considered for FBN1 mutation screening.

Methods: Our international series included 1009 probands with a known FBN1 mutation. Patients were classified as either fulfilling or not fulfilling "clinical" criteria. In patients with unfulfilled "clinical" criteria, we evaluated the percentage of additional patients who became positive for international criteria when the FBN1 mutation was considered. The aortic risk was evaluated and compared in patients fulfilling or not fulfilling the "clinical" international criteria.
\end{abstract}

Results: Diagnosis of MFS was possible on clinical grounds in $79 \%$ of the adults, whereas $90 \%$ fulfilled the international criteria when including the FBN1 mutation. Corresponding figures for children were $56 \%$ and $85 \%$, respectively. Aortic dilatation occurred later in adults with unfulfilled "clinical criteria" when compared to the Marfan syndrome group ( $44 \%$ vs $73 \%$ at 40 years, $p<0.001$ ), but the lifelong risk for ascending aortic dissection or surgery was not significantly different in both groups.

Conclusions: Because of its implications for aortic follow-up, FBN1 molecular analysis is recommended in newly suspected MFS when two systems are involved with at least one major system affected. This is of utmost importance in patients without aortic dilatation and in children.

Marfan syndrome (MFS; MIM 154700) is a connective tissue disorder with autosomal dominant inheritance and a prevalence of $1 / 5000$ individuals, ${ }^{1}$ caused mainly by FBN1 mutations. ${ }^{2}$ The cardinal features of MFS involve the ocular, cardiovascular and skeletal systems. ${ }^{3}$ The skin, lungs and dura may also be involved. In order to facilitate appropriate patient management and counselling, clinical criteria for the diagnosis of MFS were established. ${ }^{4}$ The initial criteria were proven to be too loose once molecular data became available. $^{467}$ For MFS to be diagnosed in an individual, revised diagnostic criteria were established, requiring at least two major systems affected (lens dislocation, ascending aortic dilatation or dissection, dural ectasia, a specified combination of skeletal features, family history or FBN1 mutation) and involvement of at least one other organ system (table 1). ${ }^{5}$

In practice, only clinical data are readily available and are used for initial evaluation. Reviews of patients referred for FBN1 analysis indicated that an FBN1 mutation was identified in $91 \%$ of patients when diagnosis of MFS was possible on clinical grounds; therefore, clinical data are usually specific and sufficient to establish the diagnosis of MFS in this population. ${ }^{8}$ Besides classical MFS, FBN1 mutations are also responsible for a large phenotypic spectrum ranging from neonatal Marfan syndrome to incomplete clinical entities. The latter are referred to as "other type I fibrillinopathies" and include patients with at least one system involvement but not fulfilling the clinical criteria listed in the Ghent nosology ("clinical" Ghent criteria). Therefore the question arises of when to ask for the FBN1 mutation screening in patients with incomplete phenotype since, despite technical advances, determining the presence of an FBN1 mutation remains labour intensive and costly.

From an international series of 1009 probands with a known FBN1 mutation, we assessed the contribution of molecular analyses in recognising patients at risk and suggest practical guidelines for indications for molecular analysis. We also describe the clinical characteristics of patients in whom a diagnosis can be made on clinical grounds alone, and those of patients not fulfilling "clinical" criteria, and compared the prognosis between the two groups.

\section{PATIENTS AND METHODS}

A total of 1191 probands carrying an FBN1 mutation, registered between 1995 and 2005, were identified via the Universal Marfan database FBN1 (UMD-FBN1; http:/www.umd.be) ${ }^{2} 9$ and the network of participating centres. Inclusion criteria in the present study were (1) heterozygosity for a pathogenic FBN1 gene mutation and (2) the availability of clinical information. Of 1191 probands with an FBN1 mutation, 182 probands were 
Table 1 Diagnostic criteria of Marfan syndrome according to Ghent nosology ${ }^{5}$

\begin{tabular}{|c|c|c|}
\hline Criterion & Major manifestations & Minor manifestations \\
\hline Skeletal system & $\begin{array}{l}\text { Pectus carinatum, or excavatum requiring surgery } \\
\text { - Arm span to height ratio }>1 \cdot 05 \text {, or reduced US/LS }<0.86 \\
\text { Positive wrist and thumb sign } \\
\text { - Scoliosis }>20^{\circ} \text { or spondylolisthesis } \\
\text { Limited elbow extension }<170^{\circ} \\
\text { - Flat feet } \\
4 \text { Protrusio acetabulae } \\
4 \text { of major present (system affected) }\end{array}$ & $\begin{array}{l}\text { - Facial appearance } \\
\text { - Joint hypermobility } \\
\text { - Moderate pectus excavatum } \\
\text { - High arched palate }\end{array}$ \\
\hline Ocular system & Ectopia lentis present (system affected) & $\begin{array}{l}\text { Myopia } \\
\text { - Flat cornea } \\
\text { Iris or ciliary muscle hypoplasia } \\
2 \text { of } 3 \text { minor present (system } \\
\text { involvement) }\end{array}$ \\
\hline $\begin{array}{l}\text { Cardiovascular } \\
\text { system }\end{array}$ & $\begin{array}{l}\text { Ascending aortic dilatation with or without aortic regurgitation } \\
\text { and involving the sinuses of Valsalva } \\
\text { - Ascending aortic dissection }\end{array}$ & $\begin{array}{l}\text { Mitral valve prolapse } \\
\text { Annulus mitralis calcification } \\
\text { Dilatation or dissection of } \\
\text { descending aorta or abdominal aorta } \\
\text { before } 50 \text { years } \\
\text { Dilatation of the main pulmonary } \\
\text { artery before } 40 \text { years } \\
1 \text { of } 4 \text { minor present (system } \\
\text { involvement) }\end{array}$ \\
\hline $\begin{array}{l}\text { Pulmonary } \\
\text { system }\end{array}$ & None indicated & $\begin{array}{l}\text { Pneumothorax } \\
\text { Apical blebs } \\
1 \text { of } 2 \text { minor present (system } \\
\text { involvement) }\end{array}$ \\
\hline Skin & None indicated & $\begin{array}{l}\text { Striae atrophicae } \\
\text { Recurrent or incisional herniae } \\
1 \text { of } 2 \text { minor present (system } \\
\text { involvement) }\end{array}$ \\
\hline Dural & $\begin{array}{l}\text { Lumbosacral dural ectasia } \\
\text { Dural ectasia present (system affected) }\end{array}$ & None indicated \\
\hline Family & $\begin{array}{l}\text { First degree family member independently fulfilling diagnostic } \\
\text { criteria } \\
1 \text { of } 2 \text { major present (system affected) }\end{array}$ & None indicated \\
\hline
\end{tabular}

\footnotetext{
US/LS, upper segment/lower segment.

Requirements of the diagnosis of the Marfan syndrome:

For the index case: if the family/genetic history is not contributory, major criteria in at least two different organ systems and involvement of a third organ system; if a mutation known to cause Marfan syndrome in others is detected, one major criterion in an organ system and involvement of a second organ system.

For a relative of an index case: presence of a major criterion in the family history and one major criterion in an organ system and involvement of a second organ system.
}

excluded from the study (no clinical data available in 129, insufficient data on cardiovascular, ocular or skeletal involvement in 44, autosomal dominant Weill-Marchesani syndrome in four since they represent another well defined type I fibrillinopathy, two mutations on the same allele in four, and compound heterozygosity in one) (fig 1). The patients included in the study originated from 38 different countries located across five continents. The clinical data were collected either from a questionnaire sent to referring physicians and clinical investigators or from previous publications wherein sufficient information was available. All questionnaires were collected and referenced by one individual (LF) to avoid duplication of patients in the study. The clinical information required included a range of qualitative and quantitative clinical parameters, including cardiovascular, ophthalmological, skeletal, skin, lung and dural manifestations.

For each patient, major affected system and/or minor system involvement was defined for skeletal, ocular and cardiovascular, lung, skin and dural manifestations, according to the Ghent criteria. $^{5}$ Ghent criteria were defined as positive when an isolated patient presented with two major manifestations and involvement of at least one other body system (table 1). In familial cases, the presence of a major criterion in one organ system and the involvement of a second organ system were sufficient for the diagnosis of MFS if another family member was independently diagnosed with MFS. ${ }^{5}$ In order to reproduce better the situation that clinicians face in clinical practice, the presence of an FBN1 mutation was not considered as a major 
feature in the first step. Thus, patients were classified into two groups: those who fulfilled international criteria on clinical grounds, and those who did not (fig 1). Clinical characteristics and prognosis were described in both groups. In the second step, we evaluated the percentage of patients requiring FBN1 screening for the diagnosis of MFS (fig 1). Since some of the clinical or radiological features that are used as diagnostic criteria were only occasionally investigated (protrusio acetabulae, dural ectasia, flat cornea, iris or ciliary muscle hypoplasia, dilatation of the pulmonary artery, mitral annular calcification and apical blebs), an unmentioned clinical feature was considered as absent for the determination of the patient's status. For descriptive purposes, the overall population was also classified as having neonatal MFS (defined in this study by a diagnosis of type I fibrillinopathy with severe valvular involvement before 4 weeks of age), ${ }^{10}$ severe MFS (defined by MFS diagnosis on clinical grounds with aortic dilatation before 10 years of age), probable MFS (defined by unfulfilled "clinical" criteria in childhood-that is, $<18$ years), other type I fibrillinopathies (defined by unfulfilled "clinical" criteria in adulthood), and classical MFS (defined by diagnosis of MFS on clinical grounds in other patients).

The Kaplan-Meier method was used to estimate the cumulative probabilities (and their 99.9\% confidence interval (CI)) of diagnosing ascending aortic dilatation, aortic dissection and aortic surgery at 40 years of age in order to elucidate the impact of this clinical feature over time. ${ }^{11} \mathrm{~A}$ log rank test was used to compare probabilities depending on whether patients fulfilled "clinical" Ghent criteria or not. The significance level was 0.001 .

\section{RESULTS}

The median age at diagnosis of the probands was 20 years (interquartile range (IOR) 9-33). The ages at last follow-up ranged from birth to 72 years, with a median age of 29 years (IOR 15-40). Three hundred and twenty patients were aged $<18$ years $(32 \%)$. Fifty-four per cent of patients were males and $46 \%$ were females. A family history of type I fibrillinopathy was found in $51 \%$ of cases ( $62 \%$ in the adult cohort). The population was classified as follows: $5 \%$ neonatal MFS, 7\% severe MFS, $63 \%$ classical MFS, $11 \%$ probable MFS, and $14 \%$ other type I fibrillinopathies, when the presence of an FBN1 mutation was not considered as a major feature.

Overall, the distribution of FBN1 mutations among probands (types and locations) has been described elsewhere. ${ }^{12}$ Briefly, $33 \%$ of mutations were predicted to produce a premature truncation codon and $67 \%$ an in-frame mutation. Seventy-four per cent of mutations were located in an epidermal growth factor (EGF) domain, $15 \%$ in a transforming growth factor- $\beta 1$ binding protein (TGF $\beta-B P$ ) domain, $20 \%$ in exons $24-32$ (the socalled "neonatal region"), $29 \%$ in the 5 ' region (exons 1 to 21), and $37 \%$ in the 3 ' region (exons 43 to 65 ).

The percentages of clinical features that are part of the international classification are given in table 2 . The percentages of major affected system and minor system involvement were determined in the overall population of probands, and also stratified in adults and in patients aged $<18$ years (table 3 ). Among probands, $32 \%$ had major skeletal affected system, $54 \%$ had major ocular affected system, and $77 \%$ had major cardiovascular affected system.

In the overall population of probands, diagnosis of MFS was possible on clinical grounds in $72 \%$; in an additional $17 \%$ of the population, diagnosis required FBN1 mutation screening. Analysis of adult probands only $(n=689)$ showed that diagnosis of MFS was possible on clinical grounds in $79 \%$, and in an additional $11 \%$ of the population, diagnosis required $F B N 1$ mutation screening (fig 1, fig 2A). Since only 292 patients had been examined for dural ectasia, we also studied the percentage

Figure 1 Study population and design.

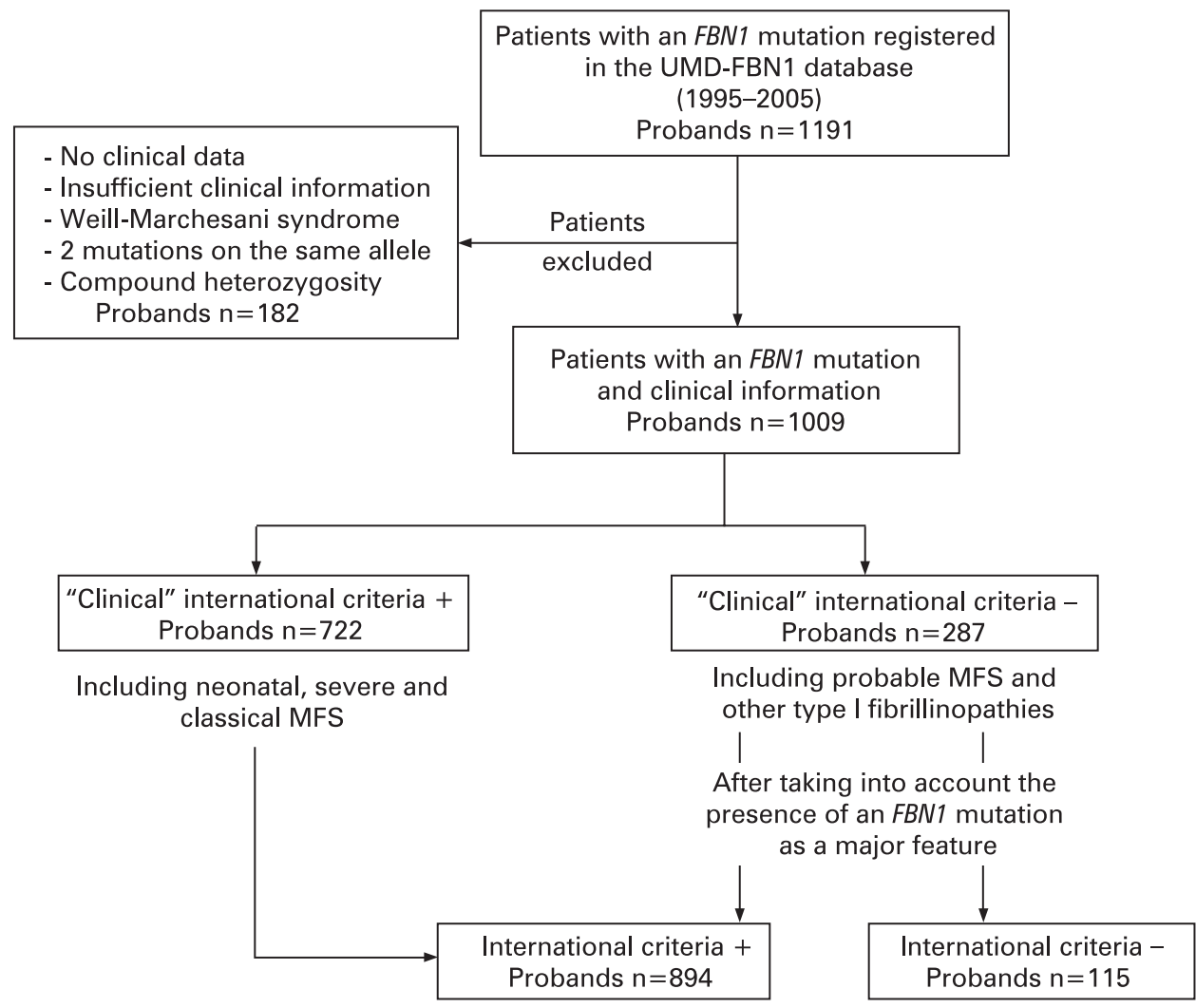


Table 2 Frequency of clinical features of the international nosology found in the 1009 probands

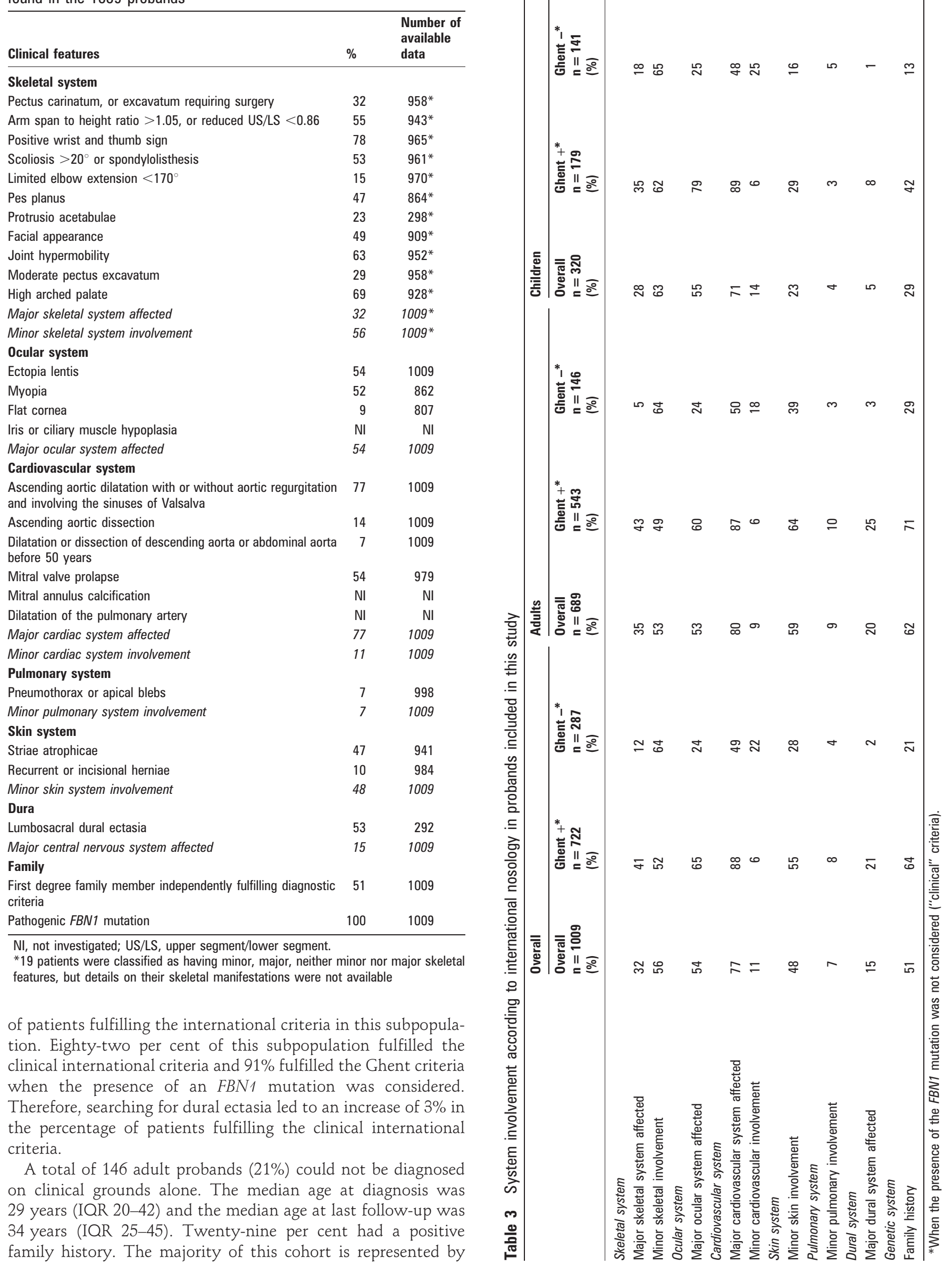


A

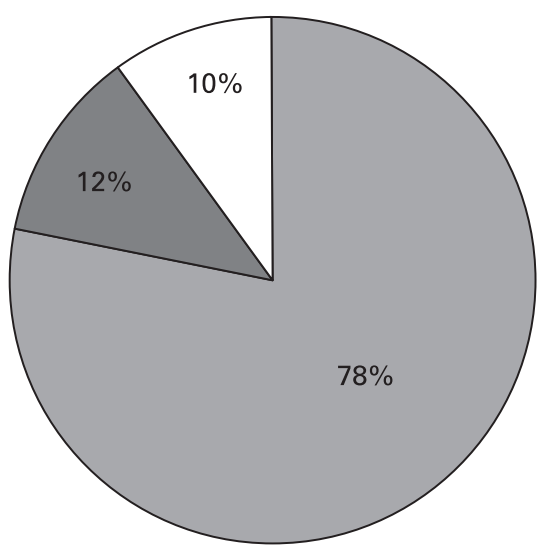

$\square$ Adult probands positive for "clinical" international criteria $\square$ Adult probands who became positive for international criteria after considering the FBN1 mutation

$\square$ Adult probands with unfulfilled international criteria after considering the FBN1 mutation

B

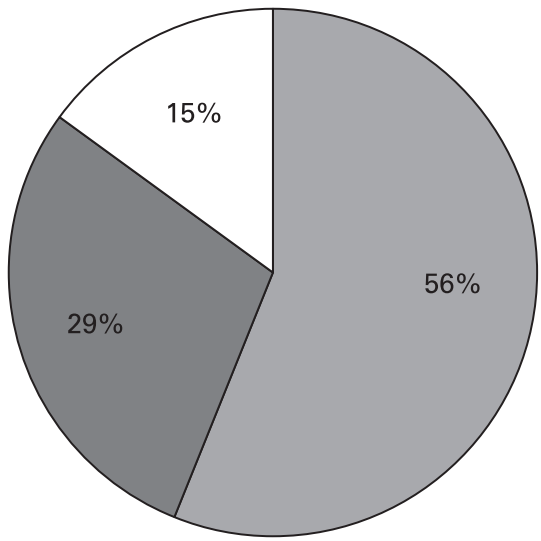

$\square$ Child probands positive for "clinical" international criteria

$\square$ Child probands who became positive for international criteria after considering the FBN1 mutation

$\square$ Child probands with unfulfilled international criteria after considering the FBN1 mutation

Figure 2 (A) Percentage of adult probands* fulfilling international criteria with or without knowledge of an FBN1 mutation $(n=689)$.

(B) Percentage of child probands fulfilling international criteria with or without knowledge of an FBN1 mutation $(n=320)$. The light grey areas represent positive probands fulfilling international criteria when the presence of a FBN1 mutation is not considered (this reflects actual clinical settings before laboratory testing). The dark grey areas represent probands fulfilling international criteria when the presence of an FBN1 mutation is considered as a major feature (actual settings after an FBN1 mutation has been identified in the proband). ${ }^{*} \geqslant 18$ years.

patients with one major system affected and at least one minor system involved $(62 \%, \mathrm{n}=90)$, and patients with two major systems affected and no minor system involved $(22 \%, n=32)$. The remaining patients had either one isolated major system affected $(5 \%, \mathrm{n}=8)$ or $\leqslant 3$ minor systems involved with no major system affected $(11 \%, n=16)$. Repartition of clinical features in the population of patients not diagnosed as MFS on clinical grounds is reported in table 3 . The molecular results made it possible to reclassify $55 \%$ of this subpopulation as MFS. Cardiac manifestations were diagnosed later than when diagnosis was possible on clinical grounds (fig 3). The cumulative probability of dilatation of the ascending aorta at 40 years was $44 \%$ (99.9\% CI 30\% to $62 \%$ ) vs $73 \%$ (99.9\% CI $66 \%$ to $79 \%$ ) (log rank test, $\mathrm{p}<0.001)$. However, the risk for aortic dissection was similar in both groups once aortic dilatation had occurred, with a cumulative probability at 40 years of $16 \%$ (99.9\% CI $4 \%$ to $39 \%$ ) vs $28 \%$ (99.9\% CI 20\% to $37 \%$ ) (log rank test, $\mathrm{p}=0.9106)$. Corresponding figures for the occurrence of aortic surgery were $34 \%$ (99.9\% CI $16 \%$ to $59 \%$ ) and $41 \%$ (99.9\% CI $32 \%$ to $50 \%$ ), respectively (log rank test, $p=0.9951$ ).

Among the 320 children, the median age at last follow-up was 10 years (IOR 5;14). Only 56\% fulfilled international diagnosis on clinical grounds whereas $85 \%$ were diagnosed as MFS when considering the presence of an FBN1 mutation (fig 2B).

\section{DISCUSSION}

Early identification of individuals at risk for aortic complications is important in view of the available medical and surgical treatments that can significantly improve the life expectancy of MFS patients. ${ }^{13}{ }^{14}$ The identification of a pathogenic FBN1 mutation confirms the presence of MFS or another type I fibrillinopathy and is a clear indicator of an aortic risk. The improvement in molecular biology and the increasing availability of FBN1 mutation screening in clinical practice allows recognition of Marfan syndrome and its inherent aortic risk in patients with incomplete phenotypes. The aims of this study were: first, to describe the clinical characteristics of a large series of 1009 genotyped probands with FBN1 mutation; and second, to evaluate the additional benefit of FBN1 mutation screening for correct diagnosis, including recognition of risk for life threatening aortic complications.

The clinical approach used in our study reproduces the situations that clinicians face in their practice when they have to decide whether molecular screening is indicated: indeed, molecular data are usually lacking when patients present for initial diagnosis. FBN1 mutation analysis adds little to the recognition of MFS patients that fulfil the clinical diagnostic criteria. ${ }^{8}$ However, our results show that a substantial group of patients harbouring an FBN1 mutation would not be recognised using clinical criteria alone. FBN1 screening is helpful in patients with a mild clinical presentation. Indeed, it permitted the reclassification of $55 \%$ of adults with unfulfilled "clinical" criteria in this study as having MFS according to international nosology. This is of particular importance since, in the group

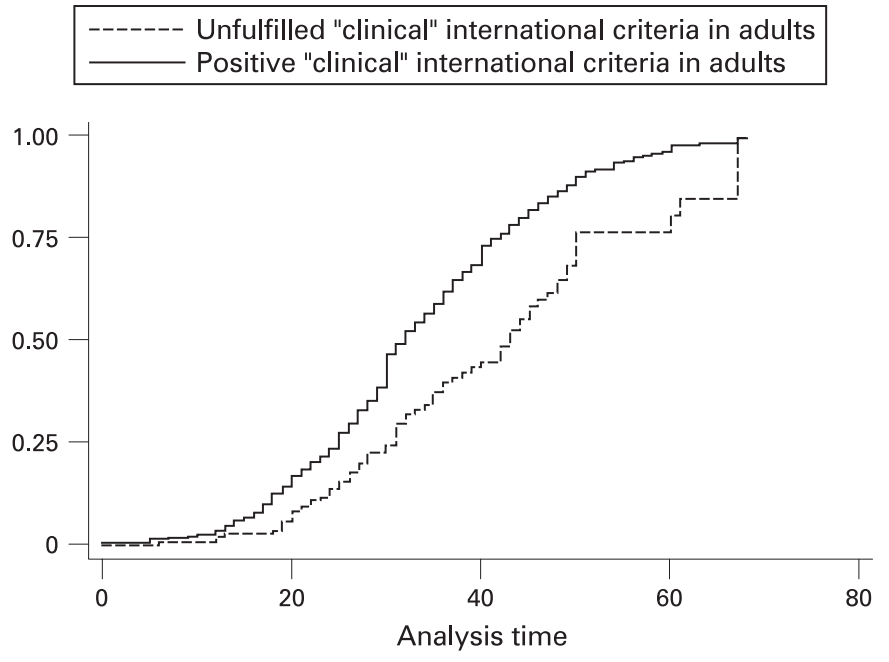

Figure 3 Cumulative probability of ascending aortic dilatation in adult probands* diagnosed on clinical grounds ( $n=541$, solid line) and in adult probands* with unfulfilled "clinical" international criteria $(n=146$, broken line) (log rank test, $\mathrm{p}<0.0001)$. ${ }^{*} \geqslant 18$ years. 
with unfulfilled "clinical" criteria, aortic dilatation is diagnosed later compared to patients fulfilling the "clinical" Ghent criteria $(p<0.001)$, while the lifelong risk for ascending aortic dissection or surgery was not significantly different.

Also, clinical evaluation is limited by the extensive phenotypic variability of the disease. ${ }^{315} 16$ Indeed, some individuals of a single family first described with "isolated" ectopia lentis developed late onset cardiovascular features, ${ }^{17}{ }^{18}$ showing that systematic cardiac follow-up should be prescribed whatever the clinical presentation associated with the FBN1 mutation. Moreover, the recurrent c.718C $>\mathrm{T}$ and c.2722T $>\mathrm{C}$ mutations described in patients with "isolated" ectopia lentis have also been found in association with ascending aortic dilatation in other patients. ${ }^{19}{ }^{20}$ Thus, FBN1 mutations are associated with an aortic risk, whatever the clinical presentation.

Results from the child cohort confirmed that the diagnosis of MFS is even more difficult in childhood since only $56 \%$ of children would have been diagnosed on clinical grounds alone. Therefore, when MFS or another type I fibrillinopathy is suspected in a child or adult, one should advocate systematic long term clinical follow-up searching for developing features in favour of the diagnosis of MFS. However, the clinical approach is limited by the risk of loss of motivation and therefore loss of follow-up in the absence of a definitive diagnosis given to the patient. Alternatively, one could recommend FBN1 screening in these populations.

For the purpose of the study, we had to consider that a clinical feature which has not been mentioned in a patient was considered as absent since only 292 patients had been examined for dural ectasia. When studying the percentages of patients fulfilling the international criteria on a clinical ground in the subpopulation of 292 fully investigated patients, 82\% fulfilled the clinical Ghent criteria as compared to $79 \%$ in the overall population, and $18 \%$ of patients still had not fulfilled the international criteria before the results of molecular studies. We therefore considered that the method used did not lead to a major bias of the results. Also, the authors are aware that there are problems associated with clinical evaluation in Marfan syndrome, in particular with the definitions of many skeletal features. Clinical tools and cut-off values are lacking for many of the clinical features and this could also lead to disparity in evaluation of the patients and therefore bias the results of the study. Nevertheless, the large majority of patients included in the study were evaluated by expert teams worldwide dealing with Marfan syndrome for many years.

In view of our results, screening for an FBN1 mutation is warranted in newly suspected MFS when two systems are involved with at least one major system affected, as it would allow for a definite diagnosis in 55\% of patients with FBN1 mutation with otherwise inconclusive diagnosis. Mutation analysis may be critical to identify patients and relatives who require life long aortic follow-up in isolated ectopia lentis or isolated major skeletal involvement. Indeed, at present, for this particular group no other known genes are involved and no clinical marker of aortic risk is available. However, when no mutation is found, patients should still have aortic follow-up as false negative analyses remain possible. On the other hand, in the case of isolated aortic dilatation, systematic aortic follow-up of patients and relatives is mandatory while FBN1 mutation screening can only be suggested for genetic counselling in view of the increasing number of genes associated with familial aortic aneurysms and overlapping syndromes. ${ }^{21-25}$ Finally, preconceptual settings might also require FBN1 mutation analysis as well as presymptomatic testing, in order to avoid unnecessary, cumbersome and costly clinical follow-up of unaffected relatives. We suggest that FBN1 molecular analysis is conducted in newly suspected MFS when two systems are involved, with at least one major system affected, in order to identify patients who require aortic follow-up. These recommendations imply that diagnostic evaluation for Marfan syndrome should be performed by someone with adequate training and expertise, and must be balanced with the availability of molecular analyses and taking into account health insurance system of a given country. Alternatively, appropriate follow-up including echocardiograms must be recommended.

In conclusion, FBN1 mutation is associated with an increased risk for aortic dilatation and dissection whatever the clinical presentation. The value of this additional risk marker when available is of particular importance when the clinical diagnosis of MFS cannot be reached, especially when aortic dilatation is not present.

Author affiliations: ${ }^{1} \mathrm{CHU}$ Dijon, Centre de Génétique, Dijon, France; ${ }^{2} \mathrm{CHU}$, Dijon, Centre d'investigation clinique - épidémiologie clinique/essais cliniques, Dijon, France: ${ }^{3}$ INSERM, U827, Montpellier, France; ${ }^{4}$ Université Montpellier1, Montpellier, France; ${ }^{5}$ Department of Cardiological Sciences, St George's Hospital, London, UK; ${ }^{6}$ Center for Medical Genetics, Ghent University Hospital, Belgium; ${ }^{7}$ Institute of Genetic Medicine and the Howard Hughes Medical Institute, Johns Hopkins University School of Medicine, Baltimore, USA; ${ }^{8}$ INSERM, CIE1, Dijon, France; ${ }^{9}$ Centre for Inherited Cardiovascular Diseases, Foundation IRCCS Policlinico San Matteo, Pavia, Italy; ${ }^{10}$ Center for Human Genetics and Laboratory Medicine, Martinsried, Germany; ${ }^{11}$ Institute of Human Genetics, Hannover Medical School, Hannover, Germany: ${ }^{12}$ AP-HP, Hôpital Ambroise Paré, Service de Pédiatrie, Boulogne, France;

${ }^{13}$ Department of Biochemistry, University of Oxford, UK; ${ }^{14} \mathrm{CHU}$ Montpellier, Hôpital Arnault de Villeneuve, Laboratoire de Génétique Moléculaire, Montpellier, France;

${ }^{15}$ Hôtel Dieu, Service de Génétique, Lyon, France; ${ }^{16}$ Institut für Medizinische Genetik, Universitätsmedizin Charité, Berlin, Germany; ${ }^{17}$ Marfan Research Group, The Children's Hospital at Westmead, Sydney, Australia; ${ }^{18}$ Discipline of Paediatrics and Child Health, University of Sydney, Sydney, Australia; ${ }^{19}$ Department of Clinical Genetics, The Children's Hospital at Westmead, Sydney, Australia; ${ }^{20}$ Departments of Genetics and Pediatrics, Stanford University Medical Center, USA; ${ }^{21}$ AP-HP, Hôpital Ambroise Paré, Laboratoire de Génétique moléculaire, Boulogne, France; ${ }^{22}$ AP-HP, Hôpital Bichat, Consultation pluridisciplinaire Marfan, Paris, France

Acknowledgements: The authors thank HC Dietz (Baltimore, USA), I Kaitila (Helsinki, Finland), P Khau Van Kien (Montpellier, France), S Davies (Cardiff, Wales) and T Uyeda (Irosaki, Japan) for their participation in the study. They also thank the patients with Marfan syndrome and their families.

Funding: This work was supported by a grant from the French ministry of health (PHRC 2004), GIS maladies rares 2004, Bourse de la Société Francaise de Cardiologie, Fédération Française de Cardiologie 2005, and ANR-05-PCOD-014. BC and BL are respectively a research fellow and a senior clinical investigator of the Fund for Scientific Research - Flanders. AC and PC thank the Marfan Trust, and the Bluff Field Charitable Fund for support.

Competing interests: None declared.

Patient consent: Patients gave consent for FBN1 mutation analysis. This study is a retrospective analysis and does not provide personal information regarding patients.

\section{REFERENCES}

1. Pyeritz RE. Marfan syndrome: current and future clinical and genetic management of cardiovascular manifestations. Semin Thorac Cardiovasc Surg 1993;5:11-6.

2. Collod-Beroud G, Le Bourdelles S, Adès L, Ala-Kokko L, Booms P, Boxer M, Child A, Comeglio P, De Paepe A, Hyland JC, Holman K, Kaitila I, Loeys B, Matyas G, Nuytinck L, Peltonen L, Rantamaki T, Robinson P, Steinmann B, Junien C, Beroud C, Boileau C. Update of the UMD-FBN1 mutation database and creation of an FBN1 polymorphism database. Hum Mutat 2003;22:199-208.

3. Judge DP, Dietz HC. Marfan's syndrome. Lancet 2005;366:1965-76

4. Beighton P, de Paepe A, Danks D, Finidori G, Gedde-Dahl T, Goodman R, Hall JG, Hollister DW, Horton W, McKusick VA, Opitz JM, Pope FM, Pyeritz RE, Rimoin DL, Sillence D, Spranger JW, Thompson E, Tsipouras P, Viljoen D, Winship I, Young I. International Nosology of Heritable Disorders of Connective Tissue, Berlin, 1986. Am J Med Genet 1988;29:581-94.

5. De Paepe A, Devereux RB, Dietz HC, Hennekam RC, Pyeritz RE. Revised diagnostic criteria for the Marfan syndrome. Am J Med Genet 1996;62:417-26.

6. Pereira L, Levran 0, Ramirez F, Lynch JR, Sykes B, Pyeritz RE, Dietz HC. A molecular approach to the stratification of cardiovascular risk in families with Marfan's syndrome. N Engl J Med 1994;331:148-53. 
7. Nijbroek G, Sood S, Mclntosh I, Francomano CA, Bull E, Pereira L, Ramirez F, Pyeritz $\mathrm{RE}$, Dietz HC. Fifteen novel FBN1 mutations causing Marfan syndrome detected by heteroduplex analysis of genomic amplicons. Am J Hum Genet 1995;57:8-21.

8. Loeys B, De Backer J, Van Acker P, Wettinck K, Pals G, Nuytinck L, Coucke P, De Paepe A. Comprehensive molecular screening of the FBN1 gene favors locus homogeneity of classical Marfan syndrome. Hum Mutat 2004;24:140-6.

9. Beroud C, Hamroun D, Collod-Beroud G, Boileau C, Soussi T, Claustres M. UMD (Universal Mutation Database): 2005 update. Hum Mutat 2005;26:184-91.

10. Hennekam RC. Severe infantile Marfan syndrome versus neonatal Marfan syndrome. Am J Med Genet A 2005;139:1.

11. Kaplan $\mathbf{E}$, Meier P. Non parametric estimation from incomplete observations. J Am Stat Assoc 1958;53:457-81.

12. Faivre L, Collod-Beroud G, Loeys BL, Child A, Binquet C, Gautier E, Callewaert B, Arbustini E, Mayer K, Arslan-Kirchner M, Kiotsekoglou A, Comeglio P, Marziliano N, Dietz HC, Halliday D, Beroud C, Bonithon-Kopp C, Claustres M, Muti C, Plauchu H, Robinson PN, Adès LC, Biggin A, Benetts B, Brett M, Holman KJ, De Baecker J, Coucke P, Francke U, De Paepe A, Jondeau G, Boileau C. Effect of mutation type and location on clinical outcome in 1013 probands with Marfan syndrome or related phenotypes with FBN1 mutations: an international study. Am J Hum Genet 2007;81:454-66.

13. Shores J, Berger KR, Murphy EA, Pyeritz RE. Progression of aortic dilatation and the benefit of long-term beta-adrenergic blockade in Marfan's syndrome. N Engl J Med 1994:330:1335-41.

14. Gott VL, Greene PS, Alejo DE, Cameron DE, Naftel DC, Miller DC, Gillinov AM, Laschinger JC, Pyeritz RE. Replacement of the aortic root in patients with Marfan's syndrome. N Engl J Med 1999;340:1307-13.

15. Robinson PN, Godfrey M. The molecular genetics of Marfan syndrome and related microfibrillopathies. J Med Genet 2000;37:9-25.

16. Robinson PN, Arteaga-Solis E, Baldock C, Collod-Beroud G, Booms P, De Paepe A, Dietz HC, Guo G, Handford PA, Judge DP, Kielty CM, Loeys B, Milewicz DM, Ney A, Ramirez F, Reinhardt DP, Tiedemann K, Whiteman P, Godfrey M. The molecular genetics of Marfan syndrome and related disorders. J Med Genet 2006;48:769-87.
17. Kainulainen K, Karttunen L, Puhakka L, Sakai L, Peltonen L.. Mutations in the fibrillin gene responsible for dominant ectopia lentis and neonatal Marfan syndrome. Nat Genet 1994;6:64-9.

18. Black C, Withers A, Gray JR, Bridges AB, Craig A, Baty DU, Boxer M. Correlation of a recurrent FBN1 mutation (R122C) with an atypical familial Marfan syndrome phenotype. Hum Mut 1998;(Suppl 1):S198-200.

19. Adès LC, Holman KJ, Brett MS, Edwards MJ, Bennetts B. Ectopia lentis phenotypes and the FBN1 gene. Am J Med Genet 2004;126:284-9.

20. Loeys B, Nuytinck L, Delvaux I, De Bie S, De Paepe A. Genotype and phenotype analysis of 171 patients referred for molecular study of the fibrillin-1 gene FBN1 because of suspected Marfan syndrome. Arch Intern Med 2001;161:2447-54.

21. Milewicz DM, Michael K, Fisher N, Coselli JS, Markello T, Biddinger A. Fibrillin-1 (FBN1) mutations in patients with thoracic aortic aneurysms. Circulation 1996;94:2708-11

22. Loeys BL, Chen J, Neptune ER, Judge DP, Podowski M, Holm T, Meyers J, Leitch CC, Katsanis N, Sharifi N, Xu FL, Myers LA, Spevak PJ, Cameron DE, De Backer J, Hellemans J, Chen Y, Davis EC, Webb CL, Kress W, Coucke P, Rifkin DB, De Paepe AM, Dietz HC. A syndrome of altered cardiovascular, craniofacial, neurocognitive and skeletal development caused by mutations in TGFBR1 or TGFBR2. Nat Genet 2005;37:275-81.

23. Pannu H, Fadulu VT, Chang J, Lafont A, Hasham SN, Sparks E, Giampietro PF, Zaleski C, Estrera AL, Safi HJ, Shete S, Willing MC, Raman CS, Milewicz DM. Mutations in transforming growth factor-beta receptor type II cause familial thoracic aortic aneurysms and dissections. Circulation 2005;112:513-20.

24. Zhu L, Vranckx R, Khau Van Kien P, Lalande A, Boisset N, Mathieu F, Wegman M, Glancy L, Gasc JM, Brunotte F, Bruneval P, Wolf JE, Michel JB, Jeunemaitre X. Mutations in myosin heavy chain 11 cause a syndrome associating thoracic aortic aneurysm/aortic dissection and patent ductus arteriosus. Nat Genet 2006;38:343-9.

25. Loeys BL, Schwarze U, Holm T, Callewaert BL, Thomas GH, Pannu H, De Backer JF, Oswald GL, Symoens S, Manouvrier S, Roberts AE, Faravelli F, Greco MA, Pyeritz RE, Milewicz DM, Coucke PJ, Cameron DE, Braverman AC, Byers PH, De Paepe AM, Dietz $\mathrm{HC}$. Aneurysm syndromes caused by mutations in the TGF-beta receptor. N Eng/ J Med 2006;355:788-98. 